\title{
Inhalt
}

Anette Baumann, Sabine Schmolinsky und Evelien Timpener

\section{Einführung -1}

Evelien Timpener

„Einem das Wasser abgraben“

Regionalkarten bei Rechtsstreitigkeiten zur Wasserregulierung — 11

Elisabeth Kisker

Territoriale Abgrenzung in Wort und Kartendarstellung

Ein westfälisches Beispiel aus dem 15./16. Jahrhundert — 29

Alexander Jendorff

Objektivierung und sozialer Sinn im Widerstreit

Herrschaftswahrnehmung, pragmatische Schriftlichkeit und die

Funktionsdivergenz des Augenscheins - 49

Anette Baumann

Beweiskommissionen und Augenscheinkarten

Strategien der Visualisierung von Inaugenscheinnahmen am

Reichskammergericht (1495-1806) - 83

Karl Härter

\section{Galgenlandschaften}

Die Visualisierung und Repräsentation von Stätten und Räumen der

Strafjustiz in bildhaften Medien der Frühen Neuzeit — 109

Claudia Hattendorff

Bild und Augenzeugenschaft

Überlegungen zu einer Nahbeziehung — 139

Joachim Kemper

Historische Kartenüberlieferung in Archiven

Von analog zu digital? - 155

Anette Baumann, Evelien Timpener und Sabine Schmolinsky

Space and law - Introduction - 165 
VIII _ Inhalt

Autorenverzeichnis 175

Abbildungsnachweise -177

Orts- und Namenregister - 181 